\title{
A TOTAL QUALITY MANAGEMENT APPROACH TO CIVIL ENGINEERING CONSULTING
}

\author{
G.A.L. Ambrose ${ }^{1}$ and S.J. Claasen ${ }^{2}$ \\ ${ }^{1}$ VIP Consulting Engineers (Pty) Ltd, South Africa \\ graeme@vipconsulting.co.za \\ ${ }^{2}$ Department of Industrial and Systems Engineering \\ University of Pretoria, South Africa \\ schalk.claasen@eng.up.ac.za.
}

\begin{abstract}
The article describes the development of a framework for the implementation of a Total Quality Management (TQM) approach in the civil consulting industry through the five phases of the typical civil engineering project. For any project to be successful the project team members must take collective and individual responsibility for their role in the project implementation. The organisational goal is "to make money now and in the future". To achieve this goal the organization must provide value to its clientele. The clients are searching for the silver bullet; double the performance at half the price. TQM provides a means to achieve this goal.
\end{abstract}

\section{OPSOMMING}

Die artikel beskryf die ontwikkeling van 'n raamwerk vir die implementering van 'n gehaltebestuurstelsel vir die siviele raadgewende bedryf soos dit deelneem aan die vyf fases van 'n tipiese siviele ingenieursprojek. Vir die suksesvolle afhandeling van 'n projek is dit noodsaaklik dat alle projekspanlede gesamentlik en afsonderlik verantwoordelikheid moet aanvaar vir hulle eie betrokkenheid by die projekimplementering. Die organisasie se oogmerk is om "nou en in die toekoms geld te maak". Ten einde hierdie oogmerk te bereik moet die organisasie waarde vir sy kliënte bied. 'n Gehaltebestuurstelsel voorsien die gereedskap om hierdie doelwit te bereik.

\footnotetext{
${ }^{1}$ This author was enrolled for the M Eng (Engineering Management) at the Department of Engineering and Technology Management, University of Pretoria
} 


\section{INTRODUCTION AND BACKGROUND}

The South African marketplace has changed dramatically since 1994, and more so since 1999. Much greater emphasis is now placed on issues such as empowerment and employment equity. Companies must embark on a process of creating diversity within the workplace, or find themselves left behind in the marketplace. The new set of market conditions demands flexible attitudes and a commitment to being part of the transformation process that is taking place in South Africa.

\section{Industry Overview}

The civil engineering consulting industry provides consulting civil engineering and project management services, which includes a number of aspects of development engineering. The industry is challenged with the task to deliver safe, innovative and cost-effective solutions to meet the need for development engineering, and provide the infrastructure required by the marketplace. In essence, what the consulting engineer does is to place at the disposal of a client, on the basis of mutual trust, their technical knowledge, experience and ability, bound by a duty to safeguard the client's interest while ensuring a sound engineering job at minimum whole life cost. This fiduciary relationship sees the engineer working wholly on behalf of the client, but consistent with a professional position that includes both a duty to the public and fairness to the contractors concerned.

The South African Association of Consulting Engineers (SAACE), in terms of its constitution and code of ethics, regulates the profession and expects members to conduct their business according to the constitution and 'good practice standards'. SAACE promotes quality-based selection (QBS) as basis for any marketing drive.

\section{Problem Statement and Objective}

The very competitive environment described above tends to be in conflict with the QBS policy of the SAACE. The limited available projects, coupled with fluctuating economic conditions, lead to 'marketing practices' that are not acceptable in terms of the SAACE code. Civil engineering consulting companies, by virtue of their professional status and membership of associations such as SAACE and the Engineering Council of South Africa (ECSA), do for the most part adhere to 'good practice standards'. Developing a Total Quality Management (TQM) approach to civil engineering consulting then should not provide major hurdles. In practice, the contrary is true and this is not a reflection on the SAACE, ECSA or even the civil consulting firms (as a whole). Rather, the players in the industry do not recognize the value of TQM, and see it as not applicable to the industry.

This article describes the development of a framework for the implementation of a TQM approach in the civil consulting industry through the five phases of the typical civil engineering project. The TQM framework defines the roles of the project team members during each of the five phases of the project:

i) Initiation - TQM begins with marketing, where the client's real needs are determined.

ii) Feasibility - feasibility studies are carried out and the issue of funding is addressed.

iii) Planning - the detailed design is completed and the tender process implemented. 
iv) Implementation - the construction monitoring stage to ensure that the designed project construction requirements are met.

v) Closure and support - entails capacity training and developing service agreements.

\section{Importance of the Topic}

The present approach leads to an us-versus-them situation during project execution. This occurs especially between the consulting engineer and the appointed contractor. A 'project team' approach needs to be developed where the focus is on project excellence. To this end, the framework must include the introduction of applicable excellence standards - such as the South African Excellence Foundation's Excellence Model or the Baldridge criteria for performance excellence. [1]

The author's experience in the civil consulting industry is that the focus is on managing output rather than the processes used to deliver the output. The standard contract documents used in the industry focus on detection and not on prevention. In order to change the focus to one of prevention, the correct questions must be asked. Replace the question, "have we done the job correctly?" with, "are we capable of doing the job correctly?" and "do we continue to do the job correctly?" [1] The first question tends to be thought of as quality control, when in practice, it becomes a wasteful ritual of pouring on 'quality' at the end of the process. The proposed approach rather seeks to answer the second question by creating a framework that will ensure that at each stage of the process the necessary capabilities are in place. Having established that the process can meet the requirements, the necessary monitoring tools and controls can be implemented to prevent failure and to ensure "doing it right the first time" at every stage of the process.

\section{Strategic Intent}

Creating a TQM framework within the five project phases aims to facilitate the proper and efficient functioning of the following aspects:

- Define the customer/supplier chain in all the project phases

- Develop TQM standards for project management

- Determine the composition of the optimal project team

- Move project management from a detection strategy to a strategy of prevention.

At the core of this framework is the customer-supplier interface, both internally and externally, where the processes at each interface must be managed. Implementation of the TQM framework holds intrinsic rewards for those who take on this long-term process: greater efficiency, lower cost, improved reputation and greater market share. These are factors that positively affect the bottom line, and thus the organization will be better able to achieve its goal "to make money now and in the future". [2] 


\section{LITERATURE SURVEY}

\section{Introduction}

Oakland and Aldridge [3] found that when literature from the construction industry as a whole was sourced, over 70 articles on quality were collated, but TQM featured in only three of these. The authors' own University of Pretoria Academic Information Search produced some 80 articles on TQM in project management, five articles were found on TQM in civil construction engineering, with only one article on TQM in civil consulting engineering. A review of the industry-based literature shows the common attitudes and feelings towards the management of quality, both in consulting civil/structural engineering and in construction generally. The literature featured is mostly characterized by a strong technical bias, with "engineers writing for engineers", where little attention is directed towards general management issues, including quality.

\section{Basic Principles of TQM}

At the core of TQM theory is the customer-supplier interface, both external and internal, and at each interface lie a number of processes. Each employee should be considered as both a customer and a supplier, since this is what happens in the everyday operation of the company. TQM treats all employees as internal customers who daily receive information, tools, equipment, materials, and services. A company, then, strives for internal excellence and customer satisfaction just as it does for external customers.

The model in figure 1 below developed by Oakland [1] incorporates the essence of TQM: The model depicts the requirements and relationships that should be in place for good quality management to be effective. At the corners of the triangle are systems, tools and teams that can be regarded as the bricks that give the model form. The "soft fluffy" components commitment, culture and communication are the mortar that connects and ensures that the model remains bound together as a working unit. At the core are depicted the customersupplier quality chains, and the processes that are extant at each interface.

TQM uses a scientific, prevention-based approach to quality improvement. The key to TQM is to harness the creative and productive power of an entire organization by releasing the workers' knowledge. Tapping this potential is accomplished through a systematic process that depends on educating the entire organization in a unique TQM process that is tailored to fit that organization. In the consulting and construction industry, the concept that education is a continuous processes must be emphasized and seen to be implemented at all levels of the organization.

The aspects of TQM most applicable to the development of a framework for the implementation of a TQM approach in the civil consulting industry are listed below:

\section{Benchmarking}

"Best practices are exemplary or successfully demonstrated ideas or activities that are viewed by at least some observers as top notch standards for guiding benchmarking" [4]. Benchmarking is the process of identifying, understanding and adopting such best practices. 


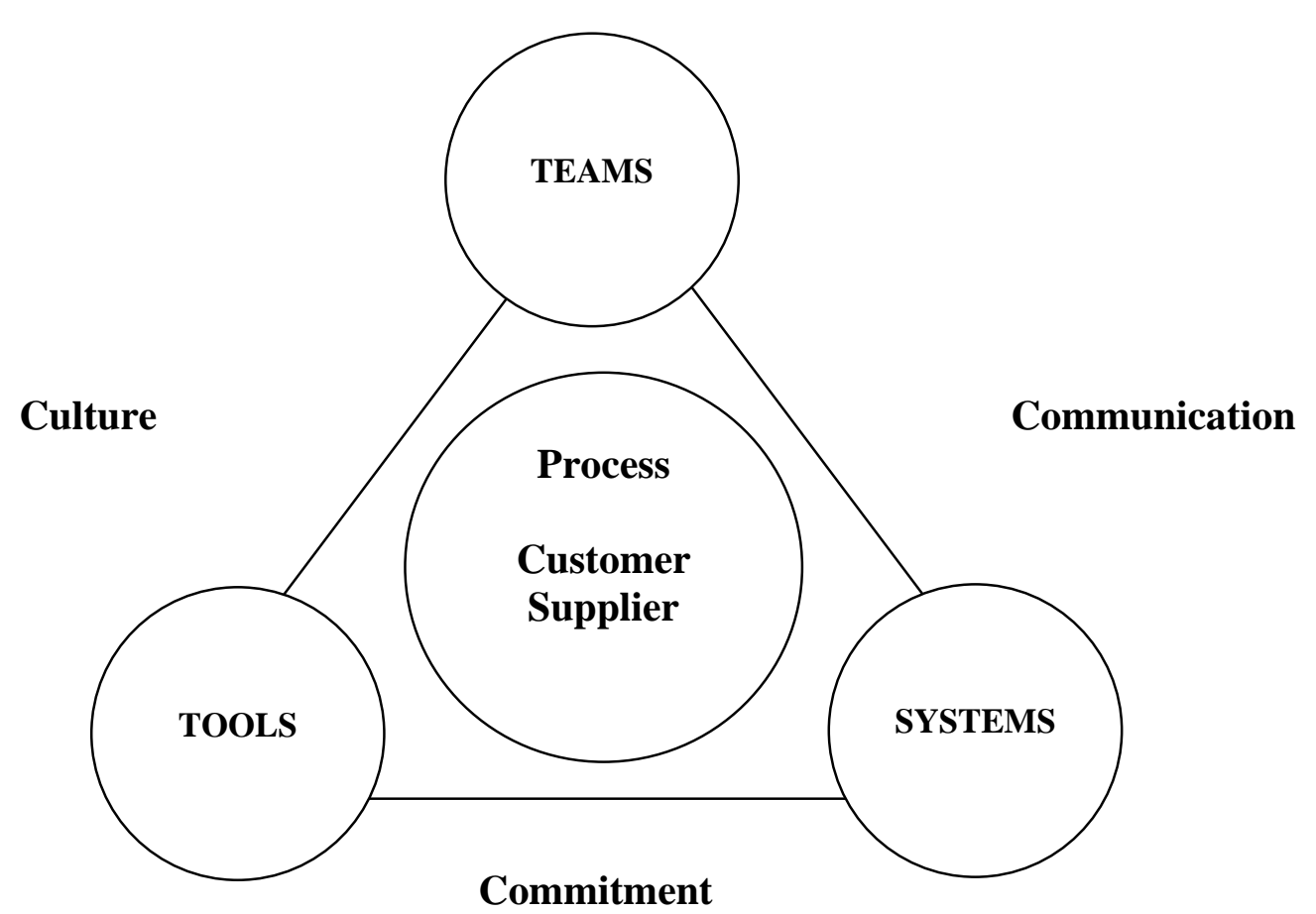

Figure 1: TQM model - major features

As in all performance improvement approaches, to achieve success, it is necessary to critically assess all the processes, and to fully understand their purpose and operation. From such a position of knowledge, it is far easier to evaluate suggested improvements, and to understand the possible impacts those changes may have on other operational areas and processes. As part of the approach to continuous improvement, a number of self-assessment frameworks or excellence models are available that set the scene for organizations to establish from where their key drivers of continuous improvement may emanate and to concentrate on them. The American Productivity and Quality Center's "Process Classification Framework" (PCF), the ISO standards for quality and environmental management (ISO 9001, ISO 14001), the European Foundation for Quality Management's Excellence Model (EFQM), the Malcolm Baldridge National Quality Award (USA) and the South African Excellence Foundation's Excellence Model (SAEF) all provide measures for self-assessment to facilitate organizations' quest for improved business performance and focus effort on their customers.

\section{Frameworks for Self-Assessment}

Self-Assessment frameworks provide a diagnostic tool for the project to assess levels of efficiency, identify gaps in the processes and institute necessary performance improvement measures to ensure project success. This requires a mind shift for all the project stakeholders in that they need to prioritise project excellence, and not their parent organization's needs. This approach requires some individual short-term sacrifices to reap the collective rewards for all project team members inherent to successful TQM application; greater efficiencies, lower cost, improved reputation and greater market share. The model uses a good governance approach that produces world-class results through sound leadership, focusing on policy and strategy, customers and markets, the people involved in the project, the available resources, appropriate processes, supplier and partnership relations and the impact on society. 
The self-assessment instruments are a means of providing performance benchmarks. Regular internal self-assessment provides a database of information that can be used to set internal benchmarks. The total quality models provide a means to measure organizations against world-class standards.

\section{Leadership}

Leadership must be as concerned with soft aspects such as openness and sensitivity as it is with harder aspects such as analytical thinking and aggressiveness. Leadership should be concerned with: keeping the vision alive; championship and mentorship; and preparing the organisation for change.

\section{Culture}

An important aspect of the successful implementation of TQM is to review the current practices, behaviours and attitudes in the organisation and assess the fit with the TQM philosophy. A cultural audit can enable senior management to identify assets as well as liabilities in their culture.

\section{Change Management}

Few industries have shown greater resistance to change than the construction industry. The old "we've always done it this way" attitude is pervasive in the hands-on business that, when compared to others, has changed little since God contracted with Noah to build the ark [5]. The implementation of TQM requires an organisation to change its culture so it can readily adapt to and take advantage of quality practices. If an organisation fails to change its culture, then TQM may not provide the benefits as initially expected.

\section{Changing the Focus of Accountability}

One of the key areas that must receive attention if TQM is to be successfully implemented is the question of the focus of accountability. Oakland [2] has identified that for an atmosphere conducive to TQM to be created, the individuals in the organization must be educated to accept that the focus of control must move from external to internal. The individuals accept accountability for their own actions rather than seeking to apportion blame. The objective is to make everyone accountable for his own performance. Changing the focus of control of the individual from external to internal creates mature, responsible, non-victim, win-win-oriented people who are aligned with the organisation's purpose and who psychologically own the success of the enterprise. To affect this personal development and maturity among individuals should be encouraged. TQM goes beyond QA and QC; it is a company wide philosophy that empowers employees to function to their potential and be accountable for their own actions.

The reluctance of the design and construction industry to apply such a useful and advantageous tool as TQM is puzzling. The advantages and rewards of applying TQM in the industry have been proven, and a practical implementation framework is presented in this article. 


\section{THE SOUTH AFRICAN CONSTRUCTION/CONSULTING CONTEXT}

\section{Resolving the Conflict}

Projects in the design and construction industry are plagued by time and cost overruns, and consequently the industry has become an adversarial business. The existing system of project implementation frequently leads to conflicts among the parties involved in the construction and development processes, hence rendering the system devoid of effective communication and teamwork. The various disciplines should function within a team culture, guided by policies, procedures and systems while focusing on the objectives and benefits identified for the project from the outset. The skills, loyalties and orientation of professionals and practitioners in the environment of the project need to be integrated. At present, integration attempts are weak and the existing systems are riddled with a blame culture - us versus them.

Effective team culture depends also on the core customer-supplier interfaces, which form the quality chains that link every operation or process in the system. The customer-supplier interfaces in the design and construction industry are often characterized by a master-servant relationship that fuels a conflict environment. This sensitive core must of necessity be surrounded by a commitment to quality through well-supported policy, communication of the quality message through effective leadership, and recognition of the need to change the culture of organizations to create total quality.

\section{Application to the South African Context}

In the context of the application of TQM in construction in South Africa, we must be driven by the objective of attaining a similar or better output for a reduced input without compromising quality. The challenge is how to utilise less resources and achieve better quality. To achieve this objective, business processes need to be revised and systems reengineered. There must be investment in human capital, as the best systems are only as good as the people who manage those systems. Antiquated work regimes and obsolete methods must be replaced with innovation, and investment in research and development. This is true for both issues of quality management and maintaining a leading edge in best practice and global competitiveness.

The majority of serious investors in South Africa regard construction as a business that is unpredictable, competitive only in price, not quality, with too few barriers to entry for poor performers. One of the key approaches towards enhancing industry performance will be to establish quality improvement education programmes. These should contribute towards the adoption of TQM as a norm in the South African design and construction industry.

\section{RESEARCH DESIGN AND METHODOLOGY}

\section{Strategy}

The research objective is to develop a framework for the implementation of TQM in the civil consulting industry. The literature review has provided the basic theoretical background of current and related theories on the subject. The theories relevant to achieving the research 
objective have been summarized and provide a basis for investigation of the research problem. The aspects that will be investigated to facilitate TQM implementation are:

- Changing the focus of accountability;

- Developing best management practices;

- Finding methods to resolve the conflict;

- Developing the necessary competence and skills required for the project team composition.

\section{Methodology}

Case studies and interviews form the heart of this research project, and are the prime methods adopted for data acquisition. The value of illustrative case studies is that they inject reality into the conceptual framework that is developed. Case studies were complemented by a secondary source of information that involved accessing organizational data and information on projects carried out by VIP Consulting Engineers (VIP).

The research instruments used in gathering data are:

\section{- Accessing and Analyzing Organizational Data}

Current and completed project data were accessed with a view to determining the trends as far as completion time, cost overruns and any other anomalies that had occurred were concerned. The accessing of organisational data provides the background and contextual setting for the other research instruments.

\section{- Case Studies}

Four projects carried out in the area of the regional office in the Free State by VIP are analysed. These projects have been chosen on the basis of their different work scopes and implementation objectives.

\section{- Interviews}

The interviews were designed to be open ended in order to acquire the broadest possible spectrum of responses. This approach conformed to the interpretative methodology that has been adopted; one that was searching for a descriptive conceptual model rather than searching for facts through experimentation. Respondents have been selected with regard to their differences in situation and perspective within the construction industry.

\section{RESULTS: DATA COLLECTION AND ANALYSIS}

\section{Analysis of Organisational Data}

The analysis of organisational data provided some interesting perspectives on the project process. The findings most relevant to the research problem are summarized as follows: 
- Most of the projects were completed late for various reasons: some due to an increase in work scope, others due to design deficiencies and others due to poor site management on the part of the contractor executing the work.

- Many projects were characterized by adversarial sentiment, especially between the consultant (project manager) and the contractor.

- Many projects experienced cost overruns due mainly to the time elapsed between business plan formulation and funding approval, with inflation taking its toll on costs. In other cases, unknown elements such as excess rock encountered caused the cost overrun, while in a few cases, cost overruns was due to design deficiencies.

- The tender evaluations showed that many contractors are disqualified because they lack the expertise and experience to carry out the work tendered for. In some cases, tender committees appointed such contractors with alarming results.

- Skills training have for some time been a contractual requirement of projects funded by government institutions. The success of such training depends on the attitude of those facilitating the training. Where the project team has undertaken meaningful training programmes, the project has invariably benefited from the enhanced skills of the project staff.

- The community has played an ever-increasing role in determining project priority for projects funded from government sources, sometimes to the detriment of the most urgent need.

- An encouraging factor is that in most cases the client's (and where applicable the community’s) need was met.

\section{Interview Results and Analysis}

The information generated by the interviews was analysed and the common themes are summarized below:

- The consensus is that no formal TQM system is applied by any of the industry stakeholders. Some see it as not practical for this industry, but more suited to manufacture.

- All the stakeholders identified a need for skills training of personnel involved in projects to equip them to produce quality work. Furthermore, a need was also identified for formal TQM education for construction personnel, and for TQM courses to be included in tertiary qualifications offered.

- The implementation of TQM in the project process from initiation to handover must have a principal/champion for it to work. This would in most cases be the project manager (usually the consultant).

- The main factors that make production of quality construction work problematic are: 
- $\quad$ Inexperience of the site management team -stakeholder representatives are often illequipped for the on-site management task;

- $\quad$ Too few barriers to the entry of unqualified participants;

- $\quad$ Personnel are not adequately trained and in many cases not suitably qualified;

- $\quad$ There is no inherent pride in producing quality work.

- An autocratic approach is still prevalent - this needs to change to a participative and preventative approach. Anticipation of possible problem situations and appropriate action will enable the prevention of mistakes. Further measures to prevent problems that were identified are: employment of suitably qualified staff and implementation of a good quality control system.

- Confrontational and adversarial relations develop mostly during the construction stage. This occurs inevitably when the quality standards have to be enforced, rather than where the project team takes collective responsibility for quality control. Human ego is a major stumbling block, and a culture needs to be developed where people welcome having their work scrutinized.

- The focus of control must move from outside the individual to within so that project team members can accept accountability for their actions.

- The customer's need must be accurately ascertained at project inception, and meeting this need must be a primary focus throughout the project process.

- All individuals interviewed, agreed that implementing a TQM system would be beneficial to any project, as well as to the individual organizations involved. These benefits include enhanced reputation and minimized rework.

- The project process flow can only be effective if at each customer-supplier interface a customer-supplier relationship exists, and meeting the customer need is of primary importance (the quality chain effect).

\section{THE PROPOSED FRAMEWORK FOR TQM IMPLEMENTATION}

\section{Strategic Intent}

A 'Strategic Intent Radar' (figure 2) has been developed to depict certain critical success factors that need to be addressed in order for TQM to be implemented successfully. The radar indicates where the design and construction industry was in 1990, where it is now (2004), and where it should be in the near future.

The following metrics are used in the Strategic Intent Radar:

- Professional service: conduct business according to the SAACE constitution and 'good practice standards', and use quality-based selection (QBS) as basis for any marketing drive. 
- Focus of control: The focus of control must move from outside the individual to within, the objective being to make everyone accountable for their own performance.

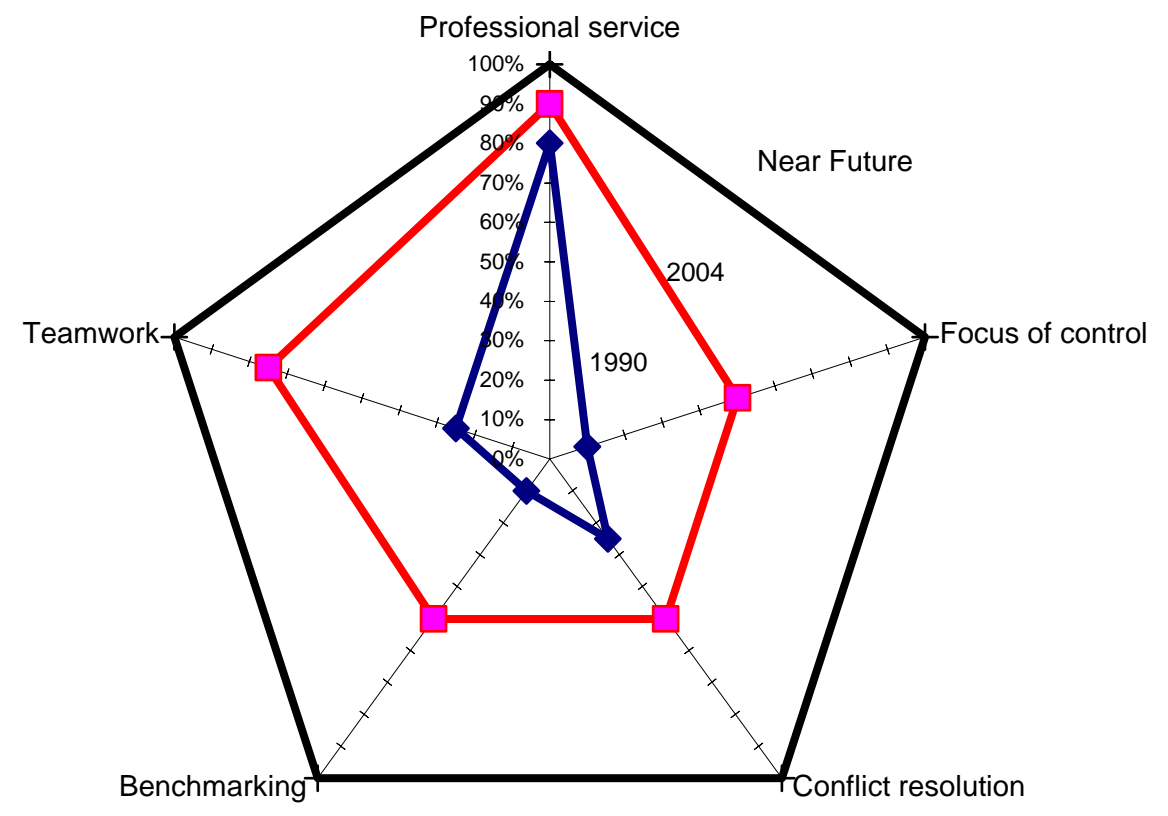

Figure 2: Strategic Intent Radar

- Conflict resolution: Be proactive to sense reasonable future changes and be prepared to act. Do not wait until being pressured into change. Look for root causes when diagnosing system malfunctions or project process bottlenecks.

- Benchmarking: Aim process improvement at the singular goal of meeting clients' expectations. Recognize the integrated and interdependent nature of the project system and implement a comprehensive results evaluation and control system that can serve as a basis for benchmarking.

- Teamwork: Learn to work smoothly in teams, i.e. respect the principle of internal customer-supplier process chains. Project teams must pursue project wide policies and dominant shared values where all employees are part of a quality culture focusing on customer satisfaction as the superordinate goal.

\section{The Framework for Implementation}

The basic requirements for the implementation of TQM in construction projects are as follows:

1. TQM must be the most important strategic issue in running the project. It must have the full support of top management.

2. A commitment to quality must be obtained from all the stakeholders - the project manager must champion the TQM implementation. The senior stakeholder management then promotes the quality focus as applicable in their individual organizations. 
3. Create and generate awareness of the TQM principles by educating project staff and changing attitudes on site.

4. Develop and document the approach to TQM for the project and communicate to all involved in the project. Strict adherence to design requirements must become the project priority.

5. Leadership must ensure that the client's voice is heard throughout the project process; this is achieved by good communications. Quality is whatever meets and develops client satisfaction and this becomes the prime focus and objective of the project.

6. Prepare project quality plans for all levels of work with the focus on prevention rather than detection of problems. Strict record must be kept of quality testing results and any instructions that have financial implications.

7. The TQM-oriented approach follows a prevention rather than detection strategy. This strategy will develop a sense of responsibility towards the project and enhance the attainment of a quality product. Avoid pouring on quality control at the end of the process.

8. Strive for internal as well as external excellence by treating all project staff as internal customers and suppliers. These customer-supplier interface links are the core of TQM application, and must be a priority of the leadership attention.

9. Change the focus of control from outside the individual to within to create mature, responsible, non-victim, win-win-oriented staff.

10. Institute continuous improvement: the key processes affecting the key specified designed requirements must be identified. By concentrating on continually improving these processes, the completion time of tasks on the critical path should be reduced.

11. Promote an integrative project culture of participation where flexibility, good communication, coherence and awareness of future options enable the quality criteria to define the project strategy. This will produce an atmosphere of cooperation on site and result in quality work being produced.

12. Review quality plans and measure performance. The project as a whole should be assessed using the PCF or SAEF assessment models to develop benchmarking standards.

13. TQM involves a radical change to strategy and culture, and affects the way people think and interact. Leadership must facilitate this radical change in paradigm for the individual stakeholders in the project process.

TQM of construction projects is an incremental process comprising a number of specific aspects. All these aspects must be integrated in a sensible and practical way. It is preferable for all project staff to be educated in TQM before the TQM approach to projects is initiated or project quality plans are implemented. The knowledge per se has no value; it must be transformed to practical skills that are useful in the everyday project application. 


\section{Application to the Five Project Phases}

The project manager (usually the consulting engineer) must lead (champion) TQM implementation in the project process through the five project phases, to ensure that the TQM approach is successfully implemented.

\section{- Initiation}

TQM begins with marketing, and a good marketing plan will incorporate ascertaining the real needs of the client. The project team at this point consists of the client and consulting engineer.

\section{- Feasibility}

Preliminary investigations and the preliminary design report assess the feasibility of the client's need being met. The question of funding is addressed, which entails that a funding agent is added to the project team.

\section{- Design}

The detailed design is completed and converted to working drawings and documentation. This incorporates optimizing the design to maximize the value to the client at the least cost. The project specification should contain any variations and additions to the standard specifications applicable to the particular project, in order to facilitate TQM application during construction.

The tender process is then pursued to find the right contractor to add to the project team. The tenders are assessed to determine whether the contractors have the necessary skills to execute the work. The client makes the final choice of contractor that is appointed.

\section{- Implementation}

The project team makeup is thus completed, and the project staff must be made aware of the importance of applying the TQM principles. A comprehensive quality control system, focusing on the prevention rather than the detection of quality problems, should be implemented. Project performance must be monitored on a regular basis using the selfassessment instruments described above as basis. Proper records of such self-assessments will provide future performance benchmarks.

The workforce engaged must be properly skilled to enable quality work to be produced; which ultimately will lead to less conflict. The culture of individual responsibility will enable the move from an external to internal focus of control. The customer-supplier interfaces are the core of TQM, and their proper function must be facilitated at each level to ensure smooth application of the TQM system.

\section{- Closure and Support}

On project closure, the asset is handed over to the client. It must be determined whether the client has the capacity to maintain the asset, and where applicable, the training of client staff 
is facilitated. Continual in-house training and formal TQM education throughout the project process will accomplish the continuous improvement approach.

\section{CONCLUSION}

A Total Quality Management System is a common sense documentation of the controls that are implemented at the various stages of the product/service delivery process. For this reason, a TQM system is equally applicable to a company with a staff complement of one or of 500 . During January 2003, Annexure A to The SAACE Constitution was revised. It now requires that Members of the South African Association of Consulting Engineers, in conducting their practices as consulting engineers and allied professionals, shall: "Implement and maintain a system of quality management in their practices". In the advisory note 03.03 sent to members on 5 September 2003, the implementation of ISO 9001:2000 is advocated to achieve this objective. ISO 9001:2000 is a comprehensive, internationally recognized approach to managing and controlling any company in order to ensure customer satisfaction and the delivery of a quality product and service.

To implement TQM, all the stakeholders involved in a project must become part of a team whose goal is the success of the project - this implies that all parties make money/achieve the anticipated benefits from the project. The SAACE initiative is commendable, but effective TQM implementation will require that all the stakeholders - the professional consulting team, the client/implementing agent, funding agent and the approved contractor - take ownership of the project and work together for the goal of project excellence.

The Total Quality Management philosophy extends beyond management systems related to the production process. It embraces the philosophy, principles, processes, practices and procedures necessary for providing comprehensive customer satisfaction, as well as achieving significant improvements in productivity and business performance. Commitment and perseverance from senior management and all project staff are necessary when embarking on the quality journey. Results will not happen overnight; it will take time to adapt, change and learn.

The mission statement of SAACE: "Enhanced Quality of Life Through Engineering Excellence" sums up what the adoption of a TQM culture strives to achieve for the civil consulting industry. Now is the time for the consulting engineering profession to "plant trees under which they may never sit." [6].

\section{REFERENCES}

[1] Oakland, J.S., Total Quality Management: text with cases, 2nd edition, ButterworthHeinemann, Oxford, 2001.

[2] Goldratt, E.M., The Goal, Creda Communications, Cape Town, 1992.

[3] Oakland, J.S. and A.J. Aldridge, Quality management in civil and structural engineering consulting, International Journal of Quality \& Reliability Management, Vol. 12 No. 3, 1995. pp $32-48$.

[4] Derek H.T. Walker, Client/customer or stakeholder focus? The TQM Magazine, MCB University Press . ISSN 0954-478X Volume 12 . Number 1 . 2000 . pp. 18 - 25. 
[5] Rashid, A. and A. Aziz, The Realities of Applying TQM in the Construction Industry, Structural Survey, Volume 20 No 2, 2002. pp 88 - 96.

[6] Pheng, L.S. and P. Ke-Wei, A Framework for Implementing TQM in Construction, The TQM Magazine, Volume 8 No 5, 1996. pp 39 - 46. 